Article

\title{
Fatigue Properties of Cold-Recycled Emulsified Asphalt Mixtures Fabricated by Different Compaction Methods
}

\author{
Yingjun Jiang, Hongwei Lin *, Zhanchuang Han and Changqing Deng * \\ Key Laboratory for Special Area Highway Engineering of Ministry of Education, Chang'an University, \\ Xi'an 710064, Shaanxi, China; jyj@chd.edu.cn (Y.J.); 2016221130@chd.edu.cn (Z.H.) \\ * Correspondence: 2017121205@chd.edu.cn (H.L.); changqingdeng@chd.edu.cn (C.D.)
}

Received: 17 May 2019; Accepted: 21 June 2019; Published: 25 June 2019

\begin{abstract}
This paper focuses on investigating the fatigue properties of cold-recycled emulsified asphalt mixtures (CEAMs) designed via two different compaction methods. First, two different CEAM compaction procedures were investigated and evaluated, including the modified Marshall compaction method (MMCM) and the vertical vibration testing method (VVTM). Indirect tensile fatigue tests were then performed to research the fatigue lives of CEAMs fabricated via the two methods. Finally, a Weibull distribution was applied to analyze the fatigue test results, and the fatigue equation was constructed. The results indicated that the average mechanical strength ratio between the CEAM samples produced by VVTM and the field core samples was $>92 \%$, whereas the average ratio of the specimens shaped by the MMCM was $<65 \%$. Compared with MMCM-molded CEAMs, VVTM-fabricated CEAMs showed decreased optimal moisture and emulsified asphalt contents by $11 \%$ and $9 \%$, respectively, but exhibited improved moisture stability, anti-cracking performance, and anti-rutting performance by $4 \%, 12 \%$, and $35 \%$, respectively. The fatigue equations established on the basis of the Weibull distribution could effectively assess the fatigue life of CEAMs. The VVTM-manufactured CEAMs showed good resistance of stress change sensitivity and fatigue failure under different stress ratios. The VVTM-compacted CEAMs demonstrated increased fatigue life by $36 \%$ at a stress ratio of 0.45 and by $325 \%$ at a repeated load of $0.27 \mathrm{MPa}$ compared with the MMCM-fabricated CEAMs.
\end{abstract}

Keywords: reclaimed asphalt pavement; cold-recycled emulsified asphalt mixture; vertical vibration testing method; modified Marshall compaction method; fatigue properties

\section{Introduction}

The recycling of reclaimed asphalt pavement (RAP) has been developed worldwide because of its remarkable economic and environmental benefits [1,2]. As a valuable way to recycling RAP, cold-recycled emulsified asphalt mixtures (CEAMs) have been extensively employed in highway maintenance projects in China because of their properties of energy efficiency, environment protection, and convenient construction [3-5]. Thus, the performance of cold-recycled mixtures has been widely investigated.

The fatigue cracking of asphalt pavements has become one of the common problems of asphalt pavements due to the recently increasing axle load and traffic volume [6-8]. The fatigue characteristics of asphalt mixtures remarkably affect pavement performance [9]. Therefore, the fatigue properties of cold-recycled mixtures must be further investigated for recycled material evaluation and pavement design. Visintine et al. evaluated the effect of high percentages of RAP on the fatigue properties of recycled asphalt mixtures [10]; they found that the fatigue life of recycled asphalt mixtures increased 
when the amounts of RAP increased from $0 \%$ to $40 \%$. Thanaya et al. performed an indirect tensile fatigue test on cold asphalt mixtures that incorporated cement [11]. The addition of $1-2 \%$ cement improves the fatigue life of cold-recycled mixtures at low strain levels. Kavussi et al. studied the indirect tensile fatigue properties of recycled mixtures with bitumen emulsion and cement through an indirect tensile test [12]. The distinct fatigue models were constructed at different boundary strain levels on the basis of the experimental results. Yan et al. investigated the fatigue properties of cold-recycled mixtures by using asphalt emulsion and foam asphalt and demonstrated that the fatigue life of emulsion mixtures is longer than that of foam mixtures at low stress levels and vice versa at high stress levels [13]. Papavasiliou and Loizos demonstrated that a cold recycled pavement overlaid with asphalt concrete improved fatigue characteristics of pavement structure through test sections and laboratory analysis [14]. Gao et al. studied the fatigue behavior of cold-recycled mixtures by using digital image correlation technology [15]. Compared with hot mix asphalt mixtures, cold recycled mixtures have longer fatigue life and larger tensile strain at the failure point under lower stress levels. Scholz et al. exhibited that compared with hot asphalt mixtures, cold-recycled mixtures displayed better fatigue life and resilient modulus at similar void contents [16]. Sun et al. proposed the fatigue failure criteria of CEAMs on the basis of the indirect tensile fatigue test and proved the temporary improvement of the fatigue life of cold-recycled mixtures during the early service stage [17].

In the above studies, several approaches have been adopted to determine the optimum emulsified asphalt and moisture contents, including the modified Marshall compaction method (MMCM) and the kneading and gyratory compaction method. However, MMCM visibly lags behind the traffic development and is poorly correlated with field performance because of its inconsistency with the vibration compaction of the on-site directional vibratory roller [18,19]. Although the samples prepared by kneading and gyratory compaction are more consistent with the field cores, the experiment device is difficult to promote universally because of its high cost [20-22]. The vertical vibration testing method (VVTM) displays good simulation of the working state of the vibration roller, and vertical vibration testing equipment (VVTE) is economical [20,23]. VVTM has been successfully applied to several road materials in some studies, such as asphalt mixtures [24-26], RAP treated with cement or emulsified asphalt [27,28], and crushed rock stabilized with inorganic or organic binders [29-31]. The mixture samples molded by VVTM exhibits good mechanical and fatigue properties.

The impression of the compaction method on the fatigue properties of CEAMs has not been explored. Thus, the present study aimed to investigate the fatigue properties of CEAMs via MMCM and VVTM. The reliability of VVTM was demonstrated through comparing the mechanical characteristics of the laboratory samples and the field cores. Subsequently, the laboratory performance of the samples manufactured via VVTM and MMCM was evaluated. Finally, the indirect tensile fatigue test was performed on CEAMs, and fatigue equations were established.

\section{Experimental Design}

\subsection{Materials}

\subsubsection{Emulsified Asphalt}

An emulsified asphalt modified with SBS (Styrene-Butadiene-Styrene) block co-polymers was used in the experimental program. The major properties reported in Table 1 were determined by applying Chinese standard test methods on bitumen and bituminous mixtures for highway engineering (JTG E20-2011) [32], which satisfied the requirements of the Chinese technical specifications for highway asphalt pavement recycling (JTG F41-2008) [33]. 
Table 1. Technical indexes of emulsified asphalt.

\begin{tabular}{|c|c|c|c|c|}
\hline \multicolumn{2}{|r|}{ Property } & Test Result & Standard & Test Method \\
\hline \multicolumn{2}{|c|}{ Demulsification rate } & Slow Setting & Slow or middle split & T0658 \\
\hline \multicolumn{2}{|c|}{ Particle charge } & + & Cation $(+)$ & T0653 \\
\hline \multicolumn{2}{|c|}{ Negra viscosity $E_{25}$} & 10.2 & $2-30$ & T0622 \\
\hline \multicolumn{2}{|r|}{$\begin{array}{c}\text { Content of residues by } \\
\text { evaporation }(\%)\end{array}$} & 63 & $\geq 62$ & T0651 \\
\hline \multirow{3}{*}{$\begin{array}{l}\text { Properties of } \\
\text { residues }\end{array}$} & Penetration $\left(25^{\circ} \mathrm{C}\right)(0.1 \mathrm{~mm})$ & 61 & $50-300$ & T0604 \\
\hline & Ductility $\left(15^{\circ} \mathrm{C}\right)(\mathrm{cm})$ & - & $\geq 40$ & T0605 \\
\hline & Solubility $(\%)$ & 98.3 & $\geq 97.5$ & T0607 \\
\hline \multirow{2}{*}{ Storage stability } & $5 \mathrm{~d}(\%)$ & 3.5 & $\leq 5$ & T0654 \\
\hline & $1 \mathrm{~d}(\%)$ & 0.6 & $\leq 1$ & T0655 \\
\hline
\end{tabular}

\subsubsection{RAP Materials}

RAP materials were obtained from the bottom layer of X115 county road in Jinhua City, Zhejiang Province, China. The gradation of these materials and the extracted aggregates are shown in Table 2. The bitumen content of the RAP was 3.8\% (mass percentage), as determined following JTG E20-2011 T0726 procedure. Table 3 shows the technical properties of the reclaimed asphalt binder recovered from RAP.

Table 2. Gradation of reclaimed asphalt pavement (RAP) materials and extracted aggregates.

\begin{tabular}{cccccccccccccc}
\hline \multicolumn{2}{c}{ Sieve Size (mm) } & $\mathbf{3 1 . 5}$ & $\mathbf{2 6 . 5}$ & $\mathbf{1 9}$ & $\mathbf{1 6}$ & $\mathbf{1 3 . 2}$ & $\mathbf{9 . 5}$ & $\mathbf{4 . 7 5}$ & $\mathbf{2 . 3 6}$ & $\mathbf{1 . 1 8}$ & $\mathbf{0 . 6}$ & $\mathbf{0 . 3}$ & $\mathbf{0 . 0 7 5}$ \\
\hline \multirow{2}{*}{ Passing (\%) } & RAP & 100 & 98.2 & 94.7 & 89.3 & 82.8 & 70.2 & 46.3 & 27.1 & 17.5 & 10.3 & 7.0 & 1.8 \\
& extracted aggregates & 100 & 100 & 98.4 & 95.5 & 86.9 & 76.2 & 59.7 & 44.2 & 31.9 & 20.6 & 15.4 & 6.8 \\
\hline
\end{tabular}

Table 3. Technical indexes of reclaimed asphalt binder recovered from RAP.

\begin{tabular}{cccc}
\hline Property & Penetration $\left.\left(\mathbf{2 5}{ }^{\circ} \mathbf{C}\right) \mathbf{( 0 . 1} \mathbf{~ m m}\right)$ & Ductility $\left.\left(\mathbf{1 5}{ }^{\circ} \mathbf{C}\right) \mathbf{( c m}\right)$ & Softening Point $\left({ }^{\circ} \mathbf{C}\right)$ \\
\hline Test value & 33.2 & 25.6 & 53.8 \\
Standard & - & - & - \\
Test method & T0604 & T0605 & T0606 \\
\hline
\end{tabular}

\subsubsection{Virgin Aggregates}

Coarse aggregates (19-26.5 mm), machine-made sand, and mineral powder were made of limestone obtained from Luonan County, Shaanxi Province, China, and were mixed with the RAP materials. The major properties shown in Tables 4-6 were tested in accordance with the Chinese test methods of aggregates for highway engineering (JTG E42-2005) [34] to satisfy the technical standards of the Chinese technical specifications for the construction of highway asphalt pavements (JTG F40-2004) [35].

Table 4. Technical indexes of coarse aggregates (19-26.5 mm).

\begin{tabular}{cccccc}
\hline Content & $\begin{array}{c}\text { Apparent Relative } \\
\text { Density }\end{array}$ & $\begin{array}{c}\text { Water Absorption } \\
\mathbf{( \% )}\end{array}$ & $\begin{array}{c}\text { Flat and Elongated } \\
\text { Particles (\%) }\end{array}$ & $\begin{array}{c}\text { Wear } \\
\text { Value (\%) }\end{array}$ & $\begin{array}{c}\text { Crushing } \\
\text { Value (\%) }\end{array}$ \\
\hline Test value & 2.732 & 0.32 & 6.1 & 15.8 & 18.4 \\
$\begin{array}{c}\text { Standard } \\
\text { Test }\end{array}$ & $\geq 2.50$ & $\leq 3.0$ & $\leq 18$ & $\leq 30$ & $\leq 28$ \\
method & T0304 & T0304 & T0312 & T0317 & T0316 \\
\hline
\end{tabular}


Table 5. Technical indexes of fine aggregates.

\begin{tabular}{ccccc}
\hline Content & $\begin{array}{c}\text { Apparent Relative } \\
\text { Density }\end{array}$ & $\begin{array}{c}\text { Sand Equivalent } \\
\mathbf{( \% )}\end{array}$ & $\begin{array}{c}\text { Angularity } \\
\text { (s) }\end{array}$ & $\begin{array}{c}\text { Methylene Blue } \\
\text { Value (g/kg) }\end{array}$ \\
\hline Test value & 2.725 & 80.3 & 43.4 & 0.8 \\
Standard & $\geq 2.50$ & $\geq 60$ & $\geq 30$ & $\leq 25$ \\
Test method & T0328 & T0334 & T0345 & T0349 \\
\hline
\end{tabular}

Table 6. Technical indexes of mineral powder.

\begin{tabular}{ccccc}
\hline Content & $\begin{array}{c}\text { Apparent } \\
\text { Relative Density }\end{array}$ & $\begin{array}{c}\text { Hydrophilic } \\
\text { Coefficient }\end{array}$ & $\begin{array}{c}\text { Water } \\
\text { Content (\%) }\end{array}$ & $\begin{array}{c}\text { Plasticity } \\
\text { Index }\end{array}$ \\
\hline Test value & 2.621 & 0.8 & 0.1 & 0.83 \\
Standard & $\geq 2.50$ & $<1$ & $\leq 1$ & $<4$ \\
Test method & T0352 & T0353 & T0345 & T0354 \\
\hline
\end{tabular}

\subsection{Gradation}

Table 7 shows the composition of the gradation of mixtures used in this work.

Table 7. Gradation of emulsified asphalt mixture.

\begin{tabular}{ccccccccccccc}
\hline \multicolumn{2}{c}{ Material Compositions/\% (Mass Percentage) } & \multicolumn{5}{c}{ Percentage Passing/\% of Sieve Sizes/mm } \\
\hline RAP & $19-26.5 \mathrm{~mm}$ & $\begin{array}{c}\text { machine- } \\
\text { made sand }\end{array}$ & $\begin{array}{c}\text { mineral } \\
\text { powder }\end{array}$ & 31.5 & 26.5 & 19 & 9.5 & 4.75 & 2.36 & 0.3 & 0.075 \\
\hline 80 & 14 & 3 & 3 & 100 & 94.8 & 83.0 & 62.2 & 42.8 & 26.6 & 9.1 & 3.9 \\
\hline
\end{tabular}

\subsection{Sample Preparation Methods and Reliability Assessment}

\subsubsection{Specimen Preparation}

Several cold-recycled mixture design procedures have been used, none of which are generally accepted [36]. The Chinese common design method and VVTM were used in this work. According to JTG F41-2008, the Chinese common design methods are the heavy hammer compaction method and MMCM. The optimum moisture content was determined by the maximum dry density in the heavy hammer compaction method [37]. The mixture samples molded by the MMCM were then tested for indirect tensile strength and immersion indirect tensile strength for the optimum emulsified asphalt content. In contrast with the common Chinese design method, VVTM determined optimum moisture on the basis of maximum dry density and emulsified asphalt contents on the basis of indirect tensile strength and immersion indirect tensile strength.

In accordance with the MMCM approved by JTG F41-2008, the mixture samples ( $\varphi 101.6 \mathrm{~mm} \times h$ $63.5 \mathrm{~mm}$ ) were first compacted by applying 50 blows of Marshall hammer at each side. After molding, all specimens were placed in the oven at $60{ }^{\circ} \mathrm{C}$ for $\geq 40 \mathrm{~h}$ to achieve constant weight. The samples were then obtained from the oven and re-compacted for 25 blows. All samples were cooled to room temperature for $12 \mathrm{~h}$ and then released from the mold. For the VVTM, all cylindrical samples $(\varphi 100 \mathrm{~mm}$ $\times h 63.5 \mathrm{~mm}$ ) were shaped with a VVTE for $60 \mathrm{~s}$. These samples were then placed in the oven at $60{ }^{\circ} \mathrm{C}$ for $48 \mathrm{~h}$ after compaction. Finally, all samples were cooled at room temperature for $12 \mathrm{~h}$ and then demolded.

\subsubsection{VVTE}

As shown in Figure 1, VVTE was composed of a control system, a rotating device, and a vibration system. The rotating device mainly included a rotation axis and an electric motor. The control system was applied to adjust the working frequency of VVTE and to control the rise and fall of the vibration system and vibration time. As the core component of VVTE, the vibration system consisted of two 
eccentric blocks, an upper and a lower system, and a vibratory hammer. Figure 2 shows that the two eccentric blocks were arranged symmetrically on the vertical plane, which inversely rotated at the same speed. Hence, the horizontal components of the centrifugal force generated by the two eccentric blocks offset each other. The vertical components were superimposed on each other to form a sinusoidal excitation force in the vertical direction, which caused the VVTE to theoretically generate a vertical vibration and reduce the shearing effect of the lateral force, ensuring the stability of the VVTE. The nominal amplitude of the VVTE could be adjusted by the lower system, and the static pressure acting on the specimen could be adjusted by the weight of the upper and lower systems so that the VVTE could maintain a satisfactory compaction effect.

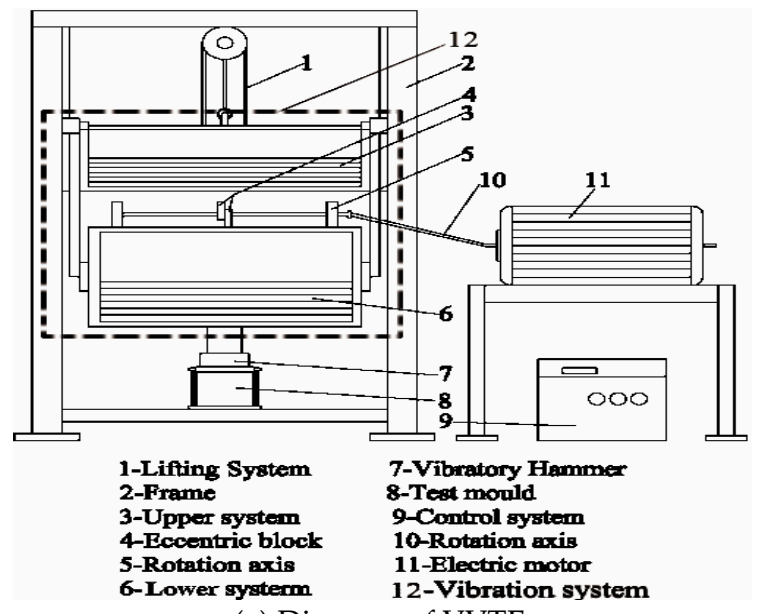

(a) Diagram of VVTE.

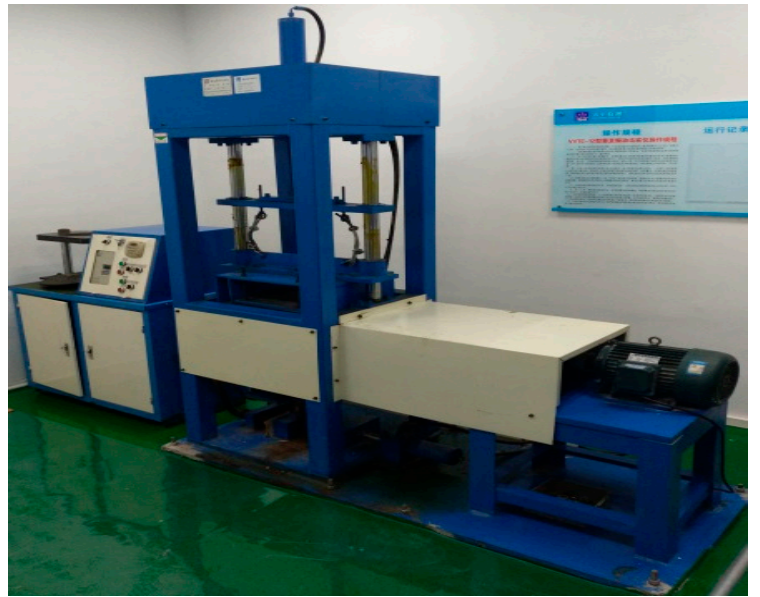

(b) Picture of VVTE in the laboratory.

Figure 1. Vertical vibration testing equipment (VVTE) schematic.

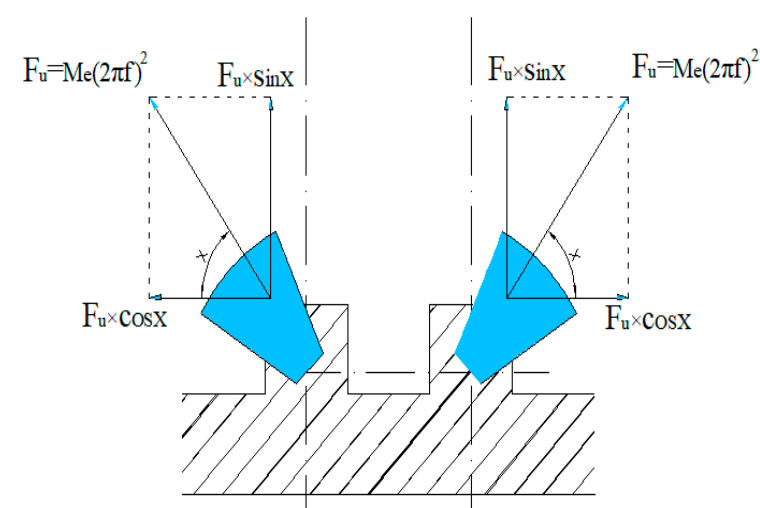

(a) Diagram of centrifugal forces.

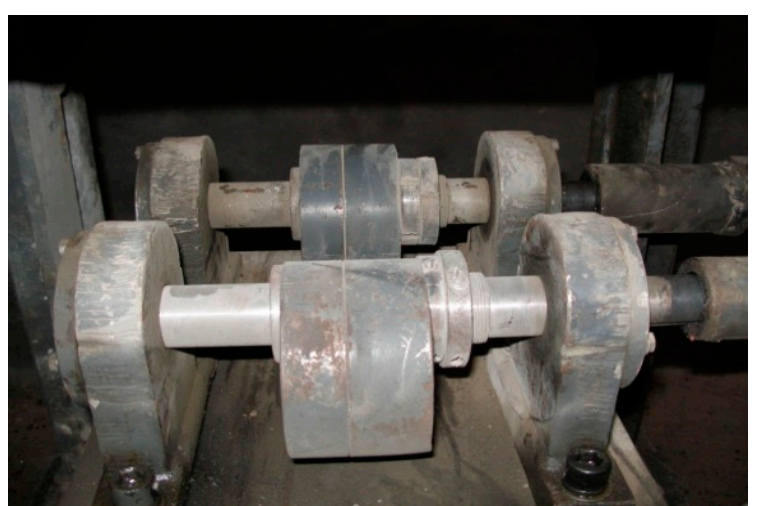

(b) Picture of eccentric blocks.

Figure 2. Eccentric blocks.

For the VVTE, the work frequency was $35 \mathrm{~Hz}$, the nominal amplitude was $1.2 \mathrm{~mm}$, and the upper and lower system weights were $108 \mathrm{~kg}$ and $167 \mathrm{~kg}$, respectively.

\subsubsection{Reliability Assessment of VVTM and MMCM}

In evaluating the reliability of a specimen molding method, the key is whether the forming method can fully simulate the actual compaction working condition and the compaction effect. Mechanical strength is one of the essential properties of CEAMs and is a basic indicator of material design and construction quality control. Therefore, this work relied on the maintenance project of X115 County Road and evaluated the reliability of VVTM and MMCM by comparing and analyzing the physical and mechanical properties of the field core samples, the VVTM-shaped samples, and the MMCM-fabricated samples. To simulate the curing condition of the CEAMs spread and rolled on-site, two types of 
CEAMs (Mixtures A and B) were obtained from two paving sites in X115 County Road. The specimens prepared indoor via VVTM and MMCM were transported to the field and cured. After the curing period, the core samples were drilled out of the pavement. The Marshall stability and indirect tensile strength of the three types of specimens were determined through six parallel tests. The results were examined and averaged through Grubbs' method. Table 8 shows the average mechanical properties of the three types of specimens, where $\mathrm{P}_{\mathrm{V}} / \mathrm{P}_{\mathrm{D}}$ refers to the ratio between the mechanical properties of the specimens produced via VVTM and the drilled core samples, and $\mathrm{P}_{\mathrm{M}} / \mathrm{P}_{\mathrm{D}}$ refers to the ratio between the mechanical properties of the specimens produced via MMCM and the drilled core samples. $V V, M S, M S_{\mathrm{I}}, R, R_{\mathrm{I}}$, and $R_{\mathrm{C}}$ are respectively denoted as the volume of air voids, Marshall stability [32], immersion Marshall stability [32], indirect tensile strength [32], immersion indirect tensile strength, and unconfined compressive strength [32].

Table 8. Mechanical properties of three types of specimens.

\begin{tabular}{|c|c|c|c|c|c|c|c|}
\hline Mixture Types & Indicators & Test Temperature $\left({ }^{\circ} \mathrm{C}\right)$ & MMCM & VVTM & Drilled Core & $\mathbf{P}_{M} / \mathbf{P}_{\mathrm{D}}(\%)$ & $\mathbf{P}_{\mathrm{V}} / \mathbf{P}_{\mathrm{D}}(\%)$ \\
\hline \multirow{6}{*}{ A } & $V V(\%)$ & - & 11.2 & 10.6 & 10.2 & - & - \\
\hline & $M S(\mathrm{kN})$ & 60 & 9.4 & 13.2 & 14.2 & 66.2 & 93.0 \\
\hline & $M S_{\mathrm{I}}(\mathrm{kN})$ & 60 & 8.3 & 12.4 & 13.4 & 61.9 & 92.5 \\
\hline & $R(\mathrm{MPa})$ & 15 & 0.61 & 0.84 & 0.91 & 67.0 & 92.3 \\
\hline & $R_{\mathrm{I}}(\mathrm{MPa})$ & 15 & 0.53 & 0.76 & 0.85 & 62.4 & 89.4 \\
\hline & $R_{\mathrm{C}}(\mathrm{MPa})$ & 20 & 0.93 & 1.32 & 1.41 & 66.1 & 93.5 \\
\hline \multirow{6}{*}{ B } & $V V(\%)$ & - & 10.9 & 10.1 & 9.7 & - & - \\
\hline & $M S(\mathrm{kN})$ & 60 & 9.6 & 13.8 & 14.7 & 65.3 & 93.9 \\
\hline & $M S_{\mathrm{I}}(\mathrm{kN})$ & 60 & 8.4 & 12.8 & 14.0 & 60.0 & 91.4 \\
\hline & $R(\mathrm{MPa})$ & 15 & 0.67 & 0.89 & 0.97 & 69.1 & 91.8 \\
\hline & $R_{\mathrm{I}}(\mathrm{MPa})$ & 15 & 0.58 & 0.83 & 0.9 & 64.4 & 92.2 \\
\hline & $R_{\mathrm{C}}(\mathrm{MPa})$ & 20 & 0.98 & 1.36 & 1.47 & 66.4 & 92.8 \\
\hline \multicolumn{2}{|c|}{ Means } & & - & - & - & 64.9 & 92.3 \\
\hline
\end{tabular}

As shown in Table 8, compared with MMCM, the $V V$ of samples molded by VVTM were closer to the field cores. Moreover, the average ratio between the mechanical strength of the samples fabricated via VVTM and the drilled core samples was $>92 \%$, whereas the average ratio of the specimens prepared via MMCM was $<65 \%$, indicating that the VVTM could simulate the field construction well and accurately predict the road performance. Hence, VVTM is a reliable technique for compacting CEAMs.

\subsection{Test Methods}

In this study, the laboratory performance measures of the CEAMs included flexural tensile strength $\left(R_{\mathrm{B}}\right)$, flexural tensile strain $\left(\varepsilon_{\mathrm{B}}\right)$, dynamic stability $(D S)$, freeze-thaw indirect tensile strength ratio (TSR), and retained Marshall stability $\left(M S_{0}\right)$. Among these indictors, $R_{\mathrm{B}}$ and $\varepsilon_{\mathrm{B}}$ reflect the anti-cracking ability of asphalt mixtures in low temperature. $D S$ evaluates the anti-rutting ability of asphalt mixtures. The moisture stability of asphalt mixtures were evaluated by TSR and $M S_{0} . R_{\mathrm{B}}, \varepsilon_{\mathrm{B}}, D S, T S R$, and $M S_{0}$ were measured in accordance with JTG E20-2011 [32]. In addition, the indirect tensile strength and fatigue properties of the asphalt mixtures were measured by the following test methods.

\subsubsection{Indirect Tensile Strength Test}

The indirect tensile strength reflects resistance to fatigue cracking, as determined via the indirect tensile fatigue test. In accordance with JTG E20-2011 T0716-2011, the cylindrical specimens were tested after $1.5 \mathrm{~h}$ of immersion in a water bath at $15{ }^{\circ} \mathrm{C}$. For the immersion indirect tensile strength test, the specimens were immersed for $23 \mathrm{~h}$ in a water bath at $25^{\circ} \mathrm{C}$ and then for $1 \mathrm{~h}$ at $15^{\circ} \mathrm{C}$. The indirect tensile strength of the CEAMs was assessed with a universal testing machine (Figure 3 ) to ensure the accuracy of the experiment. 


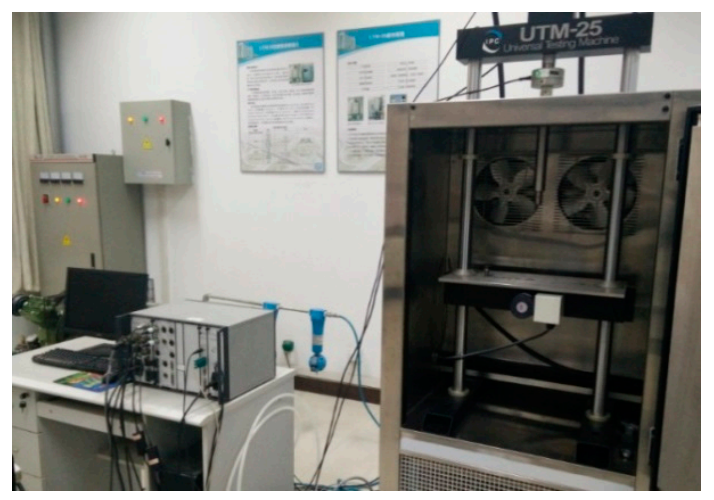

Figure 3. Universal testing machine.

Six parallel tests were conducted on the cylindrical CEAM specimens with different process designs. The results were examined and averaged through Grubbs' method. The representative values were calculated. The representative values of the indirect tensile strength with a $95 \%$ guarantee rate were defined as Ri0.95 and calculated using Equation (1) [38]:

$$
R_{0.95}=\bar{R}-1.645 S
$$

where $\bar{R}$ is the average indirect tensile strength, MPa; and $S$ is the standard deviation.

\subsubsection{Fatigue Test}

The cylindrical specimen was easier to form than the beam specimen. The stress state of the samples was similar to that of the pavement under a given load during testing [39]. Thus, the cylindrical CEAM samples were subjected to an indirect tensile fatigue test at $15^{\circ} \mathrm{C}$ by using a universal testing machine.

The stress ratio is defined as the ratio of the load force to the limit strength of the pavement materials. The experiments were performed separately at five stress ratios, namely, 0.3, 0.4, 0.5, 0.6, and 0.7. The stress-controlling mode was employed for loading, which exhibited good test reproducibility, clear definition of fatigue failure, and reliable accuracy control. The semi-vector sine wave load was adopted at a $10 \mathrm{~Hz}$ loading frequency. The peak-valley stress ratio (circulation characteristic value) under the sinusoidal wave load was 0.1 . The failure of the test piece was used as the criterion for determining fatigue failure. A schematic of the fatigue test is presented in Figure 4.

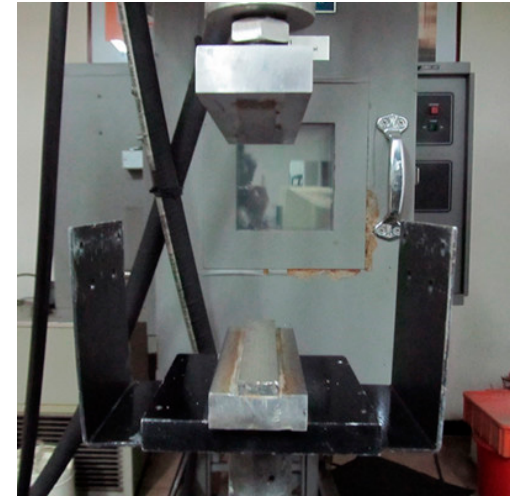

(a) Sample fixture.

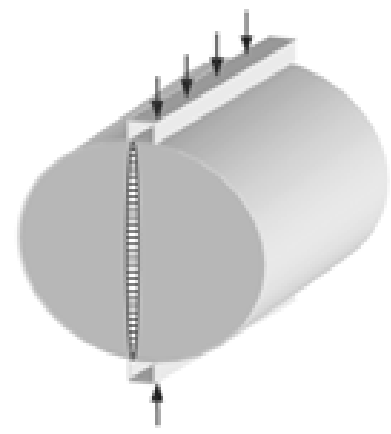

(b) Loading schematic diagram.

Figure 4. Schematic diagram of fatigue test. 


\section{Results and Discussion}

\subsection{Compaction Methods and Laboratory Evaluation}

In this work, VVTM and the Chinese common design method were used to investigate the influence of different compaction methods on the mechanical and physical properties of CEAMs.

\subsubsection{Evaluation of Physical Properties}

The mixtures were prepared with $4 \%$ emulsified asphalt content and water contents ranging from $3.5 \%$ to $5.5 \%$ at $0.5 \%$ increments. The mixtures were then compacted by the heavy hammer compaction method and VVTM, respectively. Using the maximum dry density, the optimum moisture content was determined for samples. In the next step, the emulsified asphalt was added to the mixture at percentages ranging from $3.0 \%$ to $5.0 \%$ at $0.5 \%$ increments. The samples were prepared with optimum moisture content via MMCM and VVTM separately. The optimum emulsified asphalt content was then determined on the basis of the indirect tensile strength and immersion indirect tensile strength of samples containing different emulsified asphalt content. The results on physical properties of the CEAMs fabricated via the Chinese common design method and via VVTM are listed in Table 9, where OEAC, MDD, and OMC represent the optimum moisture content, maximum dry density, and optimum emulsified asphalt content, respectively.

Table 9. Evaluation of physical properties.

\begin{tabular}{cccccc}
\hline $\begin{array}{c}\text { Compaction } \\
\text { Methods }\end{array}$ & OEAC (\%) & MDD $\left(\mathbf{g} / \mathbf{c m}^{\mathbf{3}}\right)$ & OMC (\%) & $\begin{array}{c}\text { Moisture Content } \\
\text { after Molding (\%) }\end{array}$ & $\begin{array}{c}\text { Moisture Loss } \\
\mathbf{( \% )}\end{array}$ \\
\hline VVTM & 4.2 & 2.220 & 4.30 & 4.21 & 0.09 \\
MMCM & 4.6 & 2.170 & 4.83 & 4.30 & 0.47 \\
VVTM/MMCM & 0.91 & 1.023 & 0.89 & - & - \\
\hline
\end{tabular}

As shown in Table 9, the VVTM-designed CEAMs showed decreased OEAC and OMC values by $9 \%$ and $11 \%$, respectively, and increased MDD values by $2 \%$ compared with the CEAMs designed by the Chinese common design method. The moisture loss of the VVTM-designed specimens before and after molding was only $2 \%$, whereas that of the specimens manufactured via the Chinese common design method reached 9.7\%. Excessive moisture loss would affect CEAM performance. This finding indicates that the OMC determined by the heavy hammer compaction method was extremely high, resulting in mismatch between the heavy hammer compaction method and MMCM. Therefore, VVTM is a more suitable technique than the Chinese common design method.

\subsubsection{Evaluation of Laboratory Performances}

The laboratory performances of the CEAMs manufactured via MMCM and VVTM are shown in Table 10. Six specimens with optimum emulsion and water contents were prepared for each asphalt mixture in each property test. The results were examined and averaged by Grubbs' method.

Table 10. Evaluation of laboratory performances.

\begin{tabular}{cccccc}
\hline \multirow{2}{*}{ Compaction Methods } & \multicolumn{2}{c}{ Anti-Cracking Ability } & Anti-Rutting Ability & \multicolumn{2}{c}{ Moisture Stability } \\
\cline { 2 - 6 } & $\boldsymbol{R}_{\boldsymbol{B}} \mathbf{( M P a )}$ & $\varepsilon_{\boldsymbol{B}}\left(\mu \boldsymbol{\varepsilon} \times \mathbf{1 0}^{-\mathbf{6}}\right)$ & $\boldsymbol{D S}$ (times/mm) & $\boldsymbol{M S}_{\mathbf{0}} \mathbf{( \% )}$ & TSR (\%) \\
\hline VVTM & 3.1 & 1341 & 3385 & 92.4 & 74.3 \\
MMCM & 2.3 & 1195 & 2508 & 89.1 & 71.0 \\
VVTM/MMCM & 1.35 & 1.12 & 1.35 & 1.04 & 1.05 \\
\hline
\end{tabular}

Table 10 shows that the $R_{B}, \varepsilon_{B}, D S, M S_{0}$, and TSR values of the CEAMs designed via VVTM improved by $35.0 \%, 12 \%, 35 \%, 4 \%$, and 5\%, respectively, compared to those of the MMCM design. 
This experiment result indicates that the VVTM designed asphalt mixtures achieved improvements by at least $12 \%$ and $35 \%$ in the resistance to low temperature cracking and high temperature rutting, respectively. Moreover, the moisture stability also improved. These results were due to the different underlying principles between VVTM and MMCM. The mixture particles easily form a stable and dense skeleton structure under vibration and the effect of VVTE. Therefore, the specimens molded via VVTM exhibited better performance than those prepared via MMCM.

\subsection{Fatigue Test Results and Analysis}

\subsubsection{Indirect Tensile Strength}

The indirect tensile strength of the CEAMs produced via VVTM and MMCM are presented in Table 11.

Table 11. Indirect tensile strength of cold-recycled emulsified asphalt mixtures (CEAMs).

\begin{tabular}{cccc}
\hline \multirow{2}{*}{ Compaction Methods } & \multicolumn{3}{c}{ Indirect Tensile Strength } \\
\cline { 2 - 4 } & $\overline{\boldsymbol{R}} / \mathbf{M P a}$ & Variable Coefficient/\% & $\boldsymbol{R}_{\mathbf{i} 0.95} / \mathbf{M P a}$ \\
\hline MMCM & 0.65 & 4.3 & 0.60 \\
VVTM & 0.95 & 5.3 & 0.87 \\
\hline
\end{tabular}

Table 11 demonstrates that the mixtures designed via VVTM presented better cracking resistance than those fabricated via MMCM. Compared with those of the MMCM-designed CEAMs, the $\bar{R}$ and $R_{\mathrm{i} 0.95}$ values of the VVTM-fabricated CEAMs were improved by $46 \%$ and $45 \%$, respectively.

\subsubsection{Fatigue Test}

The fatigue test results are shown in Table 12, showing the low stress ratio and long fatigue life of the MMCM- and VVTM-designed CEAMs.

Table 12. Fatigue test results of CEAMs.

\begin{tabular}{cccccc}
\hline \multirow{2}{*}{ Compaction Methods } & \multicolumn{5}{c}{ The Values of Stress Ratio $(\boldsymbol{S})$ in the List Correspond to Fatigue Life $(\boldsymbol{N})$} \\
\cline { 2 - 6 } & $\mathbf{0 . 3}$ & $\mathbf{0 . 4}$ & $\mathbf{0 . 5}$ & $\mathbf{0 . 6}$ & $\mathbf{0 . 7}$ \\
\hline \multirow{6}{*}{ MMCM } & 15,238 & 6321 & 2689 & 1292 & 628 \\
& 16,903 & 6736 & 3107 & 1522 & 733 \\
& 18,696 & 7739 & 3327 & 1674 & 816 \\
& 19,873 & 8550 & 3990 & 1959 & 879 \\
& 23,418 & 9519 & 4583 & 2444 & 1072 \\
\hline \multirow{2}{*}{ VVTM } & 18,285 & 8217 & 4302 & 2313 & 1255 \\
& 19,946 & 8757 & 4567 & 2648 & 1452 \\
& 21,313 & 9829 & 4990 & 2745 & 1574 \\
& 21,860 & 10,174 & 5307 & 2958 & 1670 \\
& 24,355 & 10,757 & 5546 & 3177 & 1790 \\
\hline
\end{tabular}

As shown in Table 12, the fatigue test data were discrete and difficult to analyze. Therefore, the fatigue life of the CEAMs was further processed by a statistical method. The Weibull distribution model is suitable for fatigue test data $[40,41]$. In this research, a two-parameter Weibull distribution was employed to process the test data.

Assuming that the equivalent fatigue life $(\bar{N})$ complies with the Weibull distribution, then the failure probability $(\mathrm{P})$ must satisfy Equation (2):

$$
\mathrm{P}=\mathrm{F}(\bar{N})=1-\exp \left(-\frac{\bar{N}^{\mathrm{m}}}{\xi}\right), \bar{N} \geq 1, \mathrm{~m}, \xi>0
$$


Equation (2) is transmuted into Equation (3) by logarithmic transformation.

$$
\ln \ln \frac{1}{1-\mathrm{P}}=\mathrm{m} \ln \bar{N}-\ln \xi=\mathrm{m}_{0} \ln N-\ln \xi
$$

where $m_{0}$ is the shape parameter, $\xi$ is the scale parameter, and $\bar{N}=N^{1-R}$.

As presented in Table 13, the regression coefficients $m_{0}, \ln \xi$, and $R^{2}$ were obtained by substituting the data in Table 12 into Equation (3). Figure 5 shows the correlation between $\ln \ln \frac{1}{1-\mathrm{P}}$ and $\ln N$.

Table 13. Fatigue test results after fitting Weibull distribution.

\begin{tabular}{ccccccc}
\hline \multirow{2}{*}{$\mathbf{S}$} & \multicolumn{3}{c}{ MMCM } & \multicolumn{3}{c}{ VVTM } \\
\cline { 2 - 7 } & $\boldsymbol{m}_{0}$ & $\ln \xi$ & $\boldsymbol{R}^{\mathbf{2}}$ & $\boldsymbol{m}_{0}$ & $\boldsymbol{l n} \xi$ & $\boldsymbol{R}^{\mathbf{2}}$ \\
\hline 0.3 & 5.3346 & 52.91 & 0.9633 & 8.1827 & 81.917 & 0.9711 \\
0.4 & 5.1782 & 46.789 & 0.9625 & 7.9023 & 72.837 & 0.9733 \\
0.5 & 4.1448 & 34.256 & 0.9622 & 8.3901 & 71.785 & 0.9825 \\
0.6 & 3.5606 & 27.018 & 0.9578 & 7.3406 & 58.598 & 0.9872 \\
0.7 & 4.3643 & 29.699 & 0.9710 & 6.4539 & 47.814 & 0.9945 \\
\hline
\end{tabular}

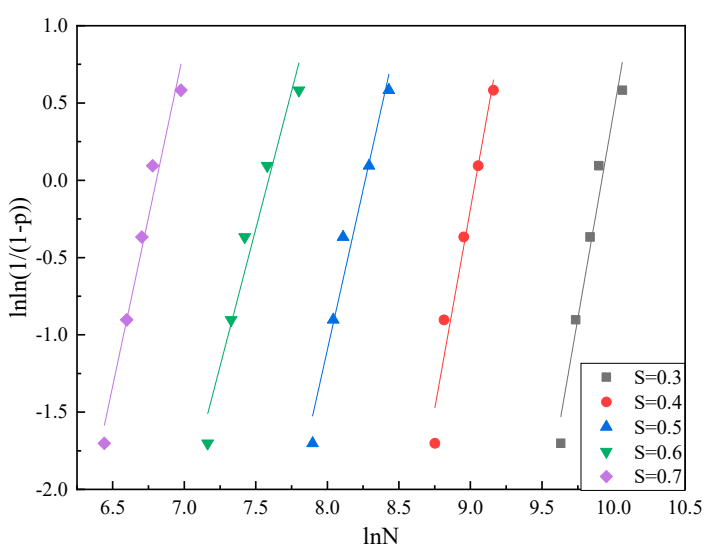

(a) MMCM.

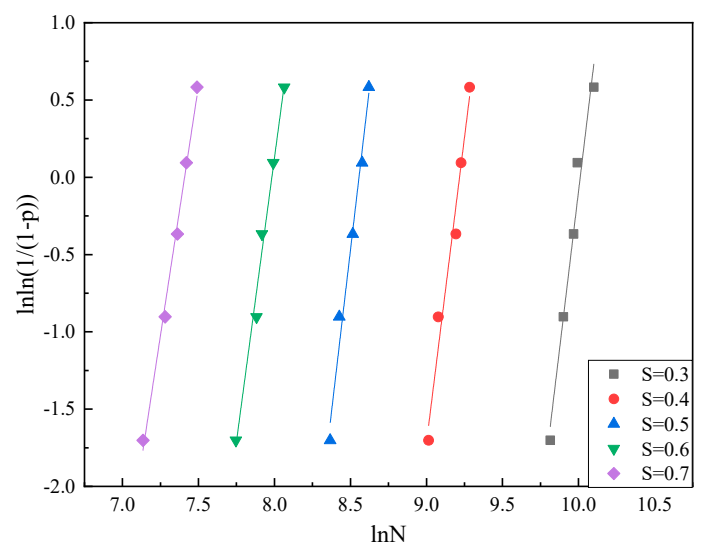

(b) VVTM.

Figure 5. Weibull fitting of fatigue test data of cold mixes specimens.

The experimental data in Table 13 indicate that the fatigue test data satisfied the Weibull distribution as the correlation coefficient $R^{2}$ reached 0.95 .

\subsubsection{Fatigue Equation}

Table 14 presents the equivalent fatigue life $(\bar{N})$ of the CEAMs prepared via VVTM and MMCM under several stress ratios and failure probabilities $(P)$ through adding the regression coefficients $m_{0}$ and $\ln \xi$ in Table 13 into Equation (3). 
Table 14. Equivalent fatigue lives of CEAMs fabricated with two methods.

\begin{tabular}{ccccccc}
\hline \multirow{2}{*}{ Compaction Methods } & $\mathbf{P}(\mathbf{\%})$ & \multicolumn{6}{c}{ The Values of $\boldsymbol{S}$ in the List } & Correspond to $\overline{\boldsymbol{N}}$ \\
\cline { 3 - 7 } & & $\mathbf{0 . 3}$ & $\mathbf{0 . 4}$ & $\mathbf{0 . 5}$ & $\mathbf{0 . 6}$ & $\mathbf{0 . 7}$ \\
\hline \multirow{3}{*}{ MMCM } & 11,632 & 4732 & 1897 & 857 & 457 \\
& 10 & 13,312 & 5438 & 2257 & 1049 & 539 \\
& 20 & 15,323 & 6286 & 2705 & 1296 & 640 \\
& 30 & 16,731 & 6882 & 3029 & 1478 & 712 \\
& 40 & 17,896 & 7376 & 3304 & 1635 & 774 \\
& 50 & 18,950 & 7824 & 3556 & 1781 & 830 \\
\hline \multirow{2}{*}{ VVTM } & 5 & 15,491 & 6914 & 3648 & 1955 & 1041 \\
& 10 & 16,915 & 7574 & 3975 & 2156 & 1164 \\
& 20 & 18,540 & 8328 & 4347 & 2388 & 1308 \\
& 30 & 19,634 & 8837 & 4596 & 2546 & 1406 \\
& 40 & 20,515 & 9248 & 4798 & 2674 & 1487 \\
& 50 & 21,295 & 9612 & 4975 & 2787 & 1559 \\
\hline
\end{tabular}

Given the apparent single/double logarithmic relationship between fatigue life $(N)$ and stress ratio $(S)$, the fatigue equation adopted in the study is shown in Equation (4):

$$
\lg N=a-b \lg S
$$

where $a$ and $b$ are the regression coefficients of the fatigue equation.

Equation (4) was employed for the regression analysis of the fatigue life data in Table 14, and the regression coefficients of Equation (4) were calculated under different failure probabilities, as shown in Table 15.

Table 15. Coefficient of fatigue equation.

\begin{tabular}{cccccccc}
\hline \multirow{2}{*}{ Compaction Methods } & \multirow{6}{*}{ Coefficient } & \multicolumn{6}{c}{ The Value of P (\%) in the List Correspond to Coefficient } \\
\cline { 2 - 8 } & & $\mathbf{5}$ & $\mathbf{1 0}$ & $\mathbf{2 0}$ & $\mathbf{3 0}$ & $\mathbf{4 0}$ & $\mathbf{5 0}$ \\
\hline \multirow{3}{*}{ MMCM } & $a$ & 2.086 & 2.1763 & 2.2706 & 2.3294 & 2.3745 & 2.4129 \\
& $b$ & 3.8671 & 3.8058 & 3.7419 & 3.7019 & 3.6713 & 3.6453 \\
& $R^{2}$ & 0.9954 & 0.9952 & 0.9945 & 0.9938 & 0.9931 & 0.9924 \\
\hline \multirow{2}{*}{ VVTM } & $a$ & 2.5752 & 2.6239 & 2.6747 & 2.7065 & 2.7308 & 2.7515 \\
& $b$ & 3.1433 & 3.1197 & 3.0951 & 3.0797 & 3.068 & 3.058 \\
& $R^{2}$ & 0.9941 & 0.9949 & 0.9957 & 0.9961 & 0.9965 & 0.9967 \\
\hline
\end{tabular}

In accordance with the regression coefficient listed in Table 15, the fatigue equation under the failure probability of 5\% and 50\% were constructed, as shown in Equations (5)-(8), which are distinguished with labels containing two characters. The first and second characters represent the type of the CEAM design procedure and the type of failure probability, respectively. For example, C5 is defined as the fatigue equation of the CEAMs manufactured via MMCM under $5 \%$ failure probability.

$$
\begin{gathered}
\text { C5: } \lg N=-3.8671 \lg S+2.086 \\
\text { V5: } \lg N=-3.1433 \lg S+2.5752 \\
\text { C50: } \lg N=-3.6453 \lg S+2.4129 \\
\text { V50: } \lg N=-3.058 \lg S+2.7515
\end{gathered}
$$

Figure 6 presents the fatigue curves of the CEAMs designed via VVTM and MMCM under the failure probability of $5 \%$ and $50 \%$ in accordance with Equations (5)-(8). The larger the regression 
coefficient $(a)$ and the smaller the regression coefficient $(b)$ in the fatigue equation, the better are the fatigue properties of the CEAMs under the stress.
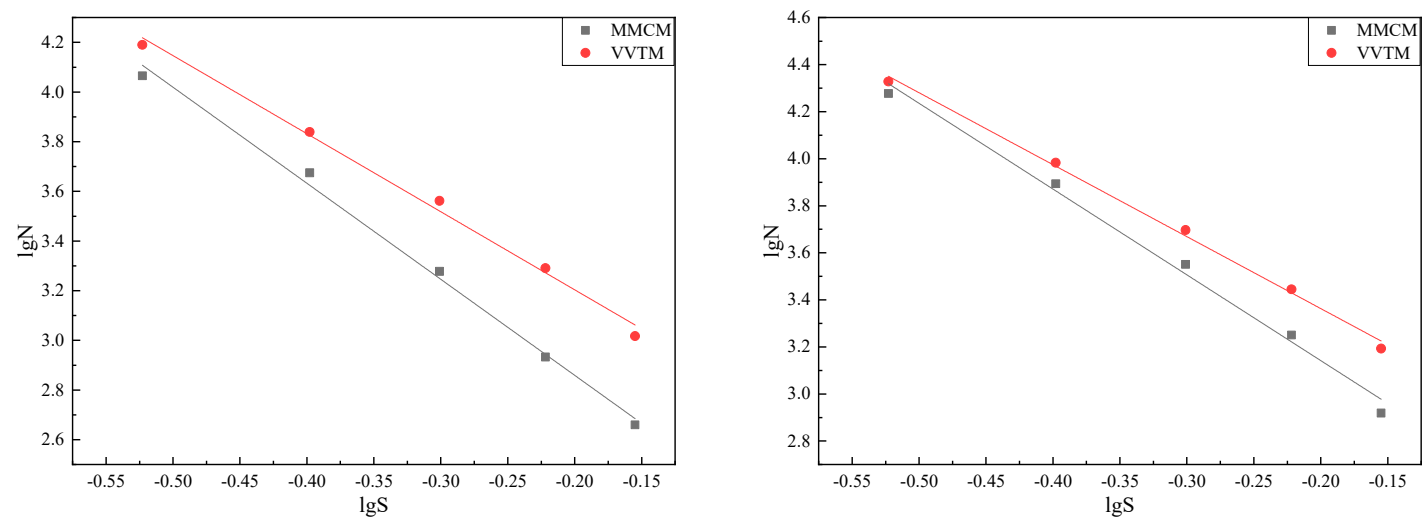

Figure 6. Fatigue curves of the CEAMs designed by the via the vertical vibration testing method (VVTM) and the modified Marshall compaction method (MMCM).

According to Table 15 and Figure $6, \lg S$ and $\lg N$ displayed a linear trend under different failure probabilities, and the correlation coefficient $R^{2}$ was $>0.90$. The regression coefficient $(a)$ was larger, and the regression coefficient $(b)$ was smaller in the fatigue equation of the VVTM-designed CEAMs compared with those of the CEAMs fabricated via MMCM under the same failure probability. This result proved that CEAMs fabricated via VVTM exhibited improved fatigue properties.

\subsubsection{Fatigue Life Analysis}

According to Table 14, the fatigue life of the CEAMs prepared via MMCM and that via VVTM under different stress ratios and failure probabilities were remarkably different, resulting in difficult quantitative analysis. The tensile stress ratio acting on the asphalt pavement under wheel load does not generally exceed 0.45 [42]. Hence, the present research investigated the fatigue life of the CEAMs at a stress ratio of 0.45 .

The effect of the indirect tensile strength on the CEAMs fabricated via MMCM and VVTM are difficult to determine by comparing the fatigue properties at a consistent stress ratio. Accordingly, analysis on the fatigue life of the CEAMs at an identical load stress was logical and necessary. The load stress of the MMCM-designed CEAMs was $0.27 \mathrm{MPa}$ at a stress ratio of 0.45 , which was calculated from the indirect tensile strength in Table 11 (load stress $=0.45 \times 0.60 \mathrm{MPa}=0.27 \mathrm{MPa}$ ). The fatigue life under a stress ratio of 0.45 or a load force of $0.27 \mathrm{MPa}$ was calculated, as shown in Table 16.

Table 16. Fatigue life of CEAMs at the same stress ratio or load stress.

\begin{tabular}{ccccc}
\hline \multirow{2}{*}{$\begin{array}{c}\text { Compaction } \\
\text { Methods }\end{array}$} & $\begin{array}{c}\text { N under the Following P (\%) When the } \\
\text { Stress Ratio is } \mathbf{0 . 4 5}\end{array}$ & $\begin{array}{c}\text { N under the Following P (\%) When the } \\
\text { Load Stress is 0.27 MPa }\end{array}$ \\
\cline { 2 - 5 } & $\mathbf{5}$ & $\mathbf{5 0}$ & $\mathbf{5}$ & $\mathbf{5 0}$ \\
\hline VVTM & 4627 & 6486 & 14,876 & 20,204 \\
MMCM & 2673 & 4754 & 2673 & 4754 \\
VVTM/MMCM & 1.73 & 1.36 & 5.57 & 4.25 \\
\hline
\end{tabular}

Table 16 indicates that the fatigue lives of the CEAM samples molded via VVTM were evidently better than those via MMCM. The fatigue life of the VVTM-designed CEAMs increased by at least $36 \%$ under a stress ratio 0.45 and by $325 \%$ under a load force $0.27 \mathrm{MPa}$ relative to that of MMCM-fabricated CEAMs.

In theory, the aggregate in the cold-recycled mixtures will gradually change from a relative static state to a relative motion state under the vibration pressure waves generated during the vibration 
process $[25,26,29]$. As internal friction resistance decreased in the CEAMs, the aggregate could fully move and interlock to form a dense framework structure. The mixtures also easily achieved compactness, and the gradation of the CEAM specimens shaped via VVTM was also near that of the field core samples $[23,31]$. Therefore, the CEAM samples shaped via VVTM displayed better mechanical and fatigue properties than those via MMCM. Furthermore, VVTM was more suitable for designing CEAM than MMCM.

\section{Conclusions}

The present study investigated the fatigue properties of the cold-recycled emulsified asphalt mixtures (CEAMs) manufactured via the vertical vibration testing method (VVTM) and the modified Marshall compaction method (MMCM). The following conclusions can be drawn on the basis of the experimental results:

(1) The average ratios of the samples produced via VVTM and MMCM to the field cores were $>92 \%$ and $<65 \%$, respectively, indicating that VVTM was more suitable for field construction than MMCM.

(2) The VVTM-fabricated CEAMs exhibited a 11\% and 9\% decrease in optimal moisture and emulsified asphalt content, respectively; and a $12 \%$ improvement in anti-cracking and a $35 \%$ improvement in anti-rutting ability compared with the MMCM-designed CEAMs. This result indicates that the VVTM-designed CEAMs showed better laboratory performances with a lower bitumen emulsion than the MMCM-designed CEAMs.

(3) The fatigue life of CEAMs was subjected to two-parameter Weibull distribution, and the fatigue equation of the CEAMs could accurately reflect the fatigue life of CEAMs.

(4) Compared with the MMCM-designed CEAMs, the VVTM-molded CEAMs demonstrated improved fatigue life by at least $36 \%$ at a stress ratio 0.45 and by $325 \%$ at a load force $0.27 \mathrm{MPa}$. This finding proves that CEAMs fabricated via VVTM exhibited longer fatigue life than those via MMCM.

The experimental results provide a new concept for CEAM design. The performance of the CEAMs fabricated with the VVTM was limited to a laboratory study and lacked long-term verification in a practical road construction project. Thus, our future research will verify the pavement performance of CEAMs manufactured through VVTM and MMCM through a long-term performance observation of an experimental road construction project.

Author Contributions: Research ideas, Y.J.; experiment design, H.L. and C.D.; experiment operation and writing—original draft preparation, H.L. and Z.H.; writing—review and editing, Y.J. and H.L.

Funding: This research is supported by the scientific project from Zhejiang Provincial Communication No. 2016-2-7, the National Natural Science Foundation of China under project No. 51408044, and the Scientific Research of Central Colleges of China for Chang'an University under project No. 300102218212. The author gratefully acknowledges its financial support.

Conflicts of Interest: The authors declare no conflict of interest.

\section{References}

1. Martinho, F; Picado-Santos, L.; Capitão, S. Feasibility Assessment of the Use of Recycled Aggregates for Asphalt Mixtures. Sustainability 2018, 10, 1737. [CrossRef]

2. Plati, C.; Cliatt, B. A Sustainability Perspective for Unbound Reclaimed Asphalt Pavement (RAP) as a Pavement Base Material. Sustainability 2019, 11, 78. [CrossRef]

3. Li, Y.; Lyv, Y.; Fan, L.; Zhang, Y. Effects of Cement and Emulsified Asphalt on Properties of Mastics and 100\% Cold Recycled Asphalt Mixtures. Materials 2019, 12, 754. [CrossRef] [PubMed]

4. Yang, Z.; Zhuang, G.; Wei, X.; Wei, J.; Yu, H.; Xu, W. Quantitative Analysis of the Blending Degree of Virgin and RAP Binders in Recycled Asphalt Mixtures with a High RAP Content. Appl. Sci. 2018, 8, 2668. [CrossRef] 
5. Ouyang, J.; Hu, L.; Li, H.; Han, B. Effect of cement on the demulsifying behavior of over-stabilized asphalt emulsion during mixing. Constr. Build. Mater. 2018, 177, 252-260. [CrossRef]

6. Li, Q.; Lee, H.J.; Kim, T.W. A simple fatigue performance model of asphalt mixtures based on fracture energy. Constr. Build. Mater. 2012, 27, 605-611. [CrossRef]

7. Shu, X.; Huang, B.; Vukosavljevic, D. Laboratory evaluation of fatigue characteristics of recycled asphalt mixture. Constr. Build. Mater. 2008, 22, 1323-1330. [CrossRef]

8. Moghaddam, T.B.; Karim, M.R.; Abdelaziz, M. A review on fatigue and rutting performance of asphalt mixes. Sci. Res. Essays. 2011, 6, 670-682. [CrossRef]

9. Bańkowski, W. Evaluation of Fatigue Life of Asphalt Concrete Mixtures with Reclaimed Asphalt Pavement. Appl. Sci. 2018, 8, 469. [CrossRef]

10. Ameri, M.; Behnood, A. Laboratory studies to investigate the properties of CIR mixes containing steel slag as a substitute for virgin aggregates. Constr. Build. Mater. 2012, 26, 475-480. [CrossRef]

11. Thanaya, I.E.A.; Zoorob, S.E.; Forth, J.P. A laboratory study on cold-mix, cold-lay emulsion mixtures. In Proceedings of the Institution of Civil Engineers: Transport; ICE Publishing: London, UK, 2009; Volume 162, pp. 47-55. [CrossRef]

12. Visintine, B.; Khosla, N.P.; Tayebali, A. Effects of higher percentage of recycled asphalt pavement on pavement performance. Road Mater. Pavement Des. 2013, 14, 432-437. [CrossRef]

13. Yan, J.; Ni, F.; Yang, M.; Li, J. An experimental study on fatigue properties of emulsion and foam cold recycled mixes. Constr. Build. Mater. 2010, 24, 2151-2156. [CrossRef]

14. Papavasiliou, V.; Loizos, A. Field performance and fatigue characteristics of recycled pavement materials treated with foamed asphalt. Constr. Build. Mater. 2013, 48, 677-684. [CrossRef]

15. Gao, L.; Ni, F.; Ling, C.; Yan, J. Evaluation of fatigue behavior in cold recycled mixture using digital image correlation method. Constr. Build. Mater. 2016, 102, 393-402. [CrossRef]

16. Scholz, T.; Rogge, D.F.; Hicks, R.G.; Allen, D. Evaluation of Mix Properties of Cold In-Place Recycled Mixes. Trans. Res. Rec. 1991, 1317, 77-89.

17. Sun, L.; Cheng, H.; Liu, L.; Cao, W. Fatigue Characteristics of In-situ Emulsified Asphalt Cold Recycled Mixtures. J. Tongji Univ Nat. Sci. Ed. 2017, 45, 1648-1654, 1687. (In Chinese) [CrossRef]

18. Tapkın, S.; Keskin, M. Rutting analysis of $100 \mathrm{~mm}$ diameter polypropylene modified asphalt specimens using gyratory and Marshall compactors. Mater. Res. 2013, 16, 546-564. [CrossRef]

19. Button, J.W.; Little, D.N.; Jagadam, V.; Pendleton, O.J. Correlation of selected laboratory compaction methods with field compaction. Trans. Res. Rec. 1994, 1454, 193-201.

20. Jiang, Y.; Chen, Z.; Xu, X.; Liang, H. Evaluation on Vertical Vibration Compaction Method of ATB-30 Asphalt Mixture. J. Build. Constr. 2014, 17, 638-643. (In Chinese) [CrossRef]

21. Georgiou, P.; Sideris, L.; Loizos, A. Evaluation of the effects of gyratory and field compaction on asphalt mix internal structure. Mater. Struct. 2016, 49, 665-676. [CrossRef]

22. Peterson, R.L.; Mahboub, K.C.; Anderson, R.M.; Masad, E.; Tashman, L. Comparing Superpave gyratory compactor data to field cores. J. Mater. Civ. Eng. 2004, 16, 78-83. [CrossRef]

23. Jiang, Y.; Xue, J.; Chen, Z. Influence of volumetric property on mechanical properties of vertical vibration compacted asphalt mixture. Constr. Build. Mater. 2017, 135, 612-621. [CrossRef]

24. Jiang, Y.; Fan, L. An experimental investigation of optimal asphalt-aggregate ratio for different compaction methods. Constr. Build. Mater. 2015, 91, 111-115. [CrossRef]

25. Jiang, Y.; Deng, C.; Li, Q.; Liu, H. Effect of Compaction Methods on Physical and Mechanical Properties of Asphalt Mixture. J. Mater. Civ. Eng. 2019, 31. [CrossRef]

26. Jiang, Y.; Deng, C.; Xue, J.; Chen, Z. Investigation into the performance of asphalt mixture designed using different methods. Constr. Build. Mater. 2018, 177, 378-387. [CrossRef]

27. Liu, H.; Jiang, Y.; Hu, Y.; Ye, W.; Cao, Z.; Cai, Y. Influence of Gradation on Strength of Emulsified Asphalt Cold Recycled Mixture. J. Build. Constr. 2018, 21, 503-510. (In Chinese) [CrossRef]

28. Ji, X.; Jiang, Y.; Liu, Y. Evaluation of the mechanical behaviors of cement-stabilized cold recycled mixtures produced by vertical vibration compaction method. Mater. Struct. 2015, 49, 2257-2270. [CrossRef]

29. Xu, X.; Cao, F.; Xue, J.; Jiang, Y. Mix Design and Road Performance of Strong Interlocked Skeleton Close-Grained Lime-Flyash Stabilized Aggregate. Appl. Mech. Mater. 2013, 438-439, 125-130. [CrossRef]

30. Jiang, Y.J.; Fan, L.F. An investigation of mechanical behavior of cement-stabilized crushed rock material using different compaction methods. Constr. Build. Mater. 2013, 48, 508-515. [CrossRef] 
31. Jiang, Y.; Xue, J. Investigation into physical and mechanical properties of SRX-stabilised crushed rock using different compaction methods. Int. J. Pavement Eng. 2017, 1-8. [CrossRef]

32. Research Institute of Highway Ministry of Transport. Standard Test Methods of Bitumen and Bituminous Mixtures for Highway Engineering (JTG E20-2011); China Communications Press: Beijing, China, 2011. (In Chinese)

33. Research Institute of Highway Ministry of Transport. Technical Specification for Highway Asphalt Pavement Recycling (JTG F41-2008); China Communications Press: Beijing, China, 2008. (In Chinese)

34. Research Institute of Highway Ministry of Transport. Test Methods of Aggregate for Highway Engineering (JTG E42-2005); China Communications Press: Beijing, China, 2005. (In Chinese)

35. Research Institute of Highway Ministry of Transport. Technical Standards of the Chinese Technical Specifications for Construction of Highway Asphalt Pavements (JTG F40-2004); China Communications Press: Beijing, China, 2004. (In Chinese)

36. Gao, L.; Ni, F.; Braham, A.; Luo, H. Mixed-Mode cracking behavior of cold recycled mixes with emulsion using Arcan configuration. Constr. Build. Mater. 2014, 55, 415-422. [CrossRef]

37. Lin, J.; Hong, J.; Xiao, Y. Dynamic characteristics of $100 \%$ cold recycled asphalt mixture using asphalt emulsion and cement. J. Clean. Prod. 2017, 156, 337-344. [CrossRef]

38. Research Institute of Highway Ministry of Transport. Testing Methods of Material Stabilized with Inorganic Binders for Highway Engineering (JTG E51-2009); China Communications Press: Beijing, China, 2009. (In Chinese)

39. Valdés, G.; Pérez-Jiménez, F.; Miró, R.; Martínez, A.; Botella, R. Experimental study of recycled asphalt mixtures with high percentages of reclaimed asphalt pavement (RAP). Constr. Build. Mater. 2011, 25, 1289-1297. [CrossRef]

40. Schijve, J. A normal distribution or a Weibull distribution for fatigue lives. Fatigue Fract. Eng. Mater. Struct. 1993, 16, 851-859. [CrossRef]

41. Zou, X.; Sha, A.; Jiang, W.; Liu, Z. Effects of modifier content on high-modulus asphalt mixture and prediction of fatigue property using Weibull theory. Road Mater. Pavement Des. 2017, 18, 88-96. [CrossRef]

42. Sun, J. Research on Fatigue Cracking Prediction Model of Asphalt Mixture Based on Stress Control Model. Master's Thesis, South China University of Technology, Guangzhou, China, June 2010. (In Chinese).

(C) 2019 by the authors. Licensee MDPI, Basel, Switzerland. This article is an open access article distributed under the terms and conditions of the Creative Commons Attribution (CC BY) license (http://creativecommons.org/licenses/by/4.0/). 